\title{
Aerodynamic and structural design of winglet with integrated VHF antenna
}

\author{
Petr Vrchota ${ }^{1, *}$, Stefan Steeger ${ }^{2}$, Marta Martinez-Vazquez ${ }^{3}$, Martin Svetlik ${ }^{4}$ and Zdenek \\ Reznicek $^{4}$ \\ ${ }^{1}$ VZLU - Czech Aerospace Research Centre, Aerodynamic Department, 19905 Prague, Czech \\ Republic \\ ${ }^{2}$ INVENT GmbH, Bussiness Unit Aviation, D-38112 Braunschweig, Germany \\ ${ }^{3}$ IMST GmbH, Department of Antennas \& EM Modelling, 47475 Kamp-Lintfort, Germany \\ ${ }^{4}$ Evektor, Engineering Service Division, 686 04, Kunovice, Czech Republic
}

\begin{abstract}
A new optimized winglet of a small aircraft is used to develop the solutions for structure, VHF antenna, systems as lights and lightning protection. The aerodynamic optimization has been based on the Design of Experiment and Response Surface method in order to find out the suitable shape of the winglet from the aerodynamic, structure and the basic operating frequency range for VHF radio communication points of view. The winglet's structure has been designed based on the aerodynamic loads and took into account the appropriate technology. The improvement of the aerodynamic characteristics and handling qualities of the aircraft are discussed and the integration concepts and production moulds are presented.
\end{abstract}

\section{Introduction}

Modern aircraft are highly efficient in terms of fuel burn and emissions. Aerodynamic efficiency is of key concern of meeting this challenge. One part of the existing aircraft which can be modified in order to further reduction of $\mathrm{CO} 2$ and NOx emissions is replacing of the protruding antennas by integrating ones [1]. The structurally integrated antennas cause less additional drag, noise and turbulence in comparison with classical protruding antennas. It also reduces the maintenance costs and operational delays avoiding to protruding parts by collisions with airport cargo cars. The European project ACASIAS [2] addresses, among others, the topic of integrated antennas and their effect on aerodynamic performances and environment. The VHF antennas can be integrated into the fuselage panels or winglet's surface, e.g. This paper is focusing on the design of the winglet enabling to integrate VHF antenna into it and its effect on aerodynamic characteristics.

\section{Methodologies}

\footnotetext{
${ }^{*}$ Corresponding author: vrchota@,vzlu.cz
} 


\subsection{Geometrical model}

Small Air Transport aircraft EV55 has been used during this study (see Fig. 1). It is a twin engine aircraft for 9 passengers. The model's simplification has been considered during this study to decrease computational resources during the optimization. The simplification consists of the omitting of the fuselage, nacelle and control surfaces. The wing with the original winglet only was used as a baseline configuration (see Fig. 1).

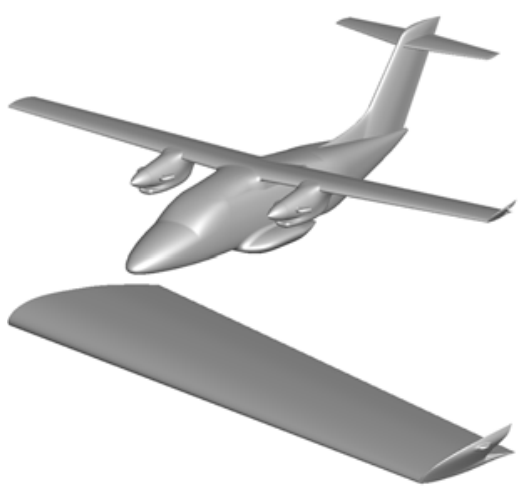

Fig.1. Baseline geometry and level of simplification

\subsection{Optimization strategy}

The optimization strategy is based on the Design of Experiment (DoE) in connection with Response Surface Method (RSM) [3-5] to find out the optimal winglet's shape from the requirements point of views. This strategy can be used in many different applications.

\subsubsection{Winglet's parameterization}

Winglet itself was parameterized by elliptic curves. Six parameters in total were used for creation of the DoE matrix. The height, dihedral, twist and its combination defined the final winglet's shape for particular design in the DoE matrix. This parameterization is depicted in

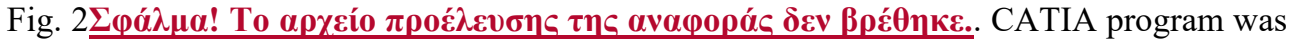
used to create all winglets' geometries used during simulations. 


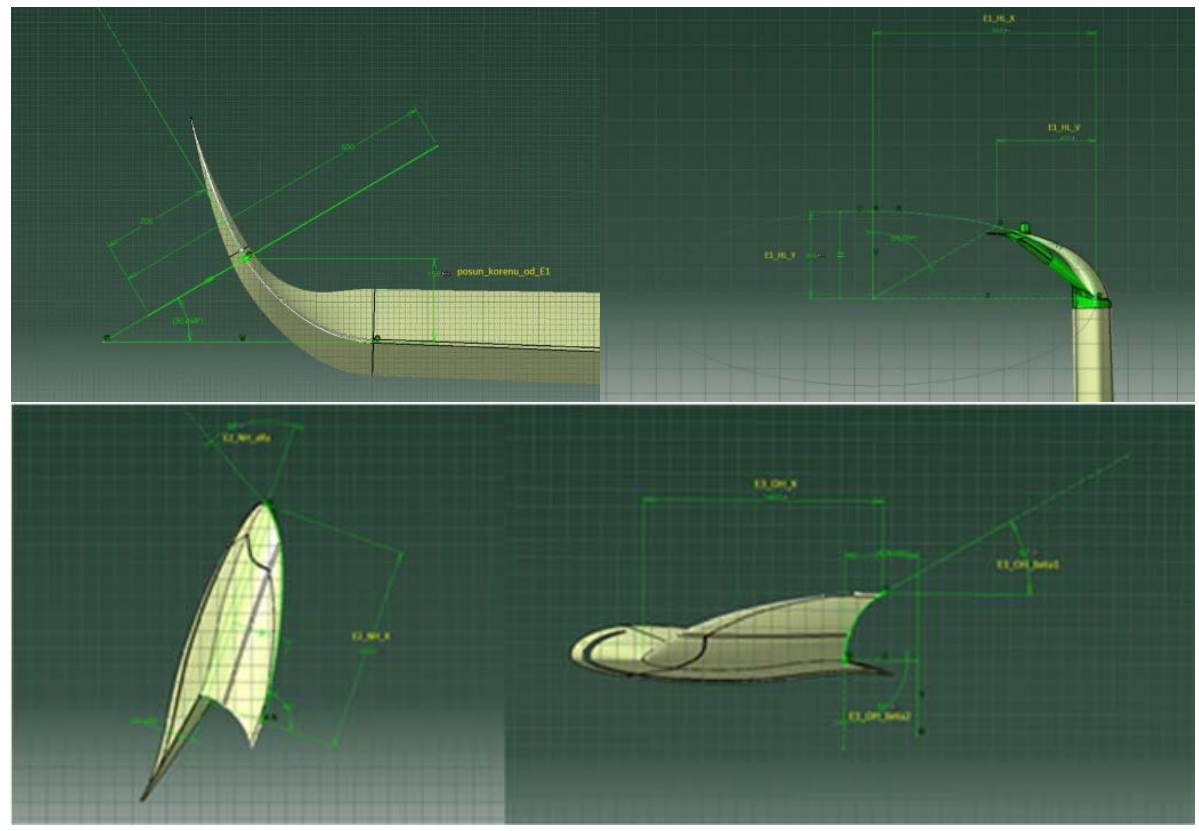

Fig.2. Winglet's parameterization

\subsubsection{Design of Experiment \& Response Surface Method}

The circumscribe type of DoE was used during this study. It uses also the designs outside the design space and therefore to enables to obtain more accurate information about the cost function also on the boundary of the design space. The circumscribe type of the design corresponding to the 3D space is depicted in Fig. 3. The limits of particular variables were determined according to the authors' experience.

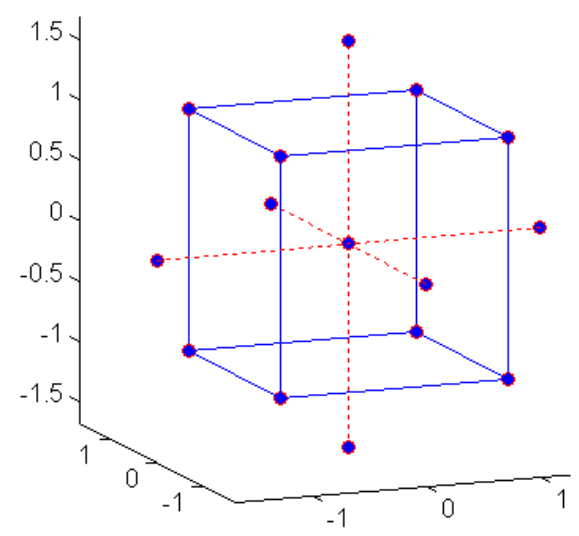

Fig.3. Circumscribe type of design space

The response surface is a second-order model containing primary effects, their interaction and quadratic effects for arbitrary $\mathrm{k}$ input factors xi and output variable $\mathrm{y}$. This model is described by following equation. 


$$
y=\beta_{0}+\sum_{j=1}^{k} \beta_{j j} x_{j j}^{2}+\sum \sum_{i<j=2}^{k} \beta_{i j} x_{i} x_{j}
$$

The input factors are selected variables $(k)$. The output variable y represents cost functions. The coefficients $\beta \mathrm{i} \beta \mathrm{ij}$, along with the interval of confidence, were obtained by the leastsquares method. The advantages of RSM are that it gives an overview of the cost function behaviour at complete design space, allows simple addition of supplemental requirements to the cost function, and requires a relatively small number of design points for the direct cost function evaluation. The cost function can be defined after evaluation of the design points. In that case, the reduction of the induced drag related to the baseline configuration was defined as the primary cost function. The spanwise lift distribution was also checked due to the not to overload of the wing.

\section{Results}

208 winglet's geometries in total were evaluated in several optimization steps by means of CFD simulations. A RANS method was used to calculate the flowfield, aerodynamic coefficients and loading. The angle of attack during the winglet's optimization was 4 deg. The velocity of the incoming flow corresponded to the cruise velocity of EV55.

\subsection{Aerodynamic results}

The optimization resulted in the winglet's shape with the highest reduction of the induced drag for the considered AoA. The difference in drag related to the baseline configuration without winglet is 5 drag counts and related to the original winglet 2 drag counts, respectively. Due to the horn aerodynamic balance of the aileron the winglet is attached to the wing in the first quarter of its chord and the slot between the aileron and winglet is modelled. This slot generates relatively strong vortices, which are depicted in Fig. 4. The baseline geometry with original winglet does not have this slot. It could be the reason for relatively smaller drag reduction of the optimized winglet. The other reason for smaller drag reduction is the wetted surface of the new winglet which is much larger than the wetted surface of the original winglet. The new winglet is approximately 2.38 times larger than the original one. The streamwise component of skin friction coefficient with the surface streamlines is depicted also in Fig. 4. The comparison of the original and optimized winglets' shapes is depicted in Fig. 5.
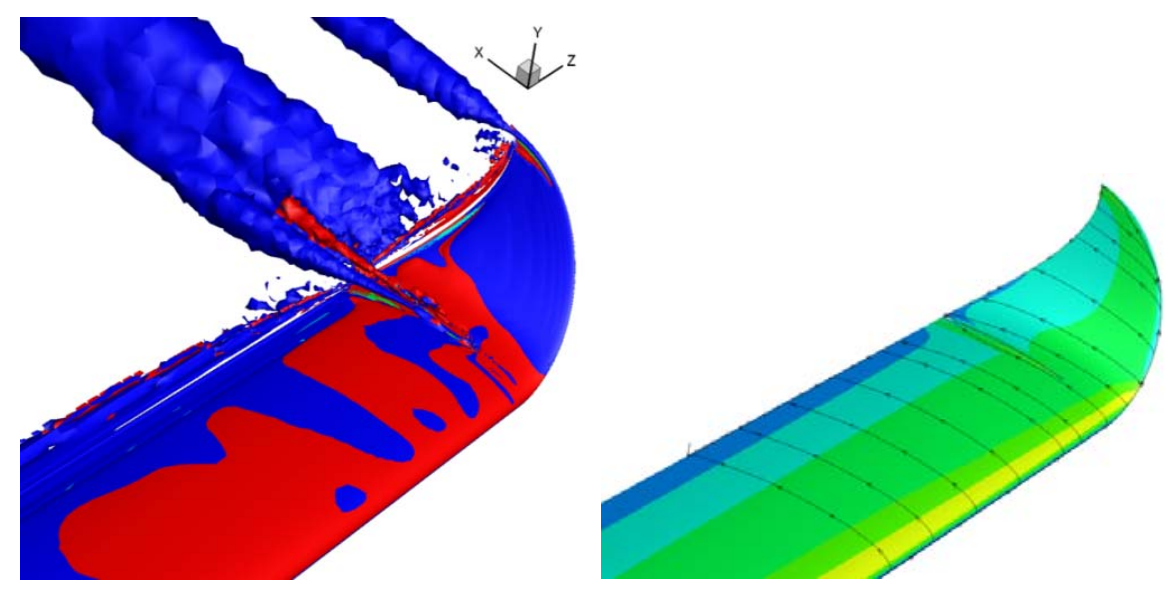

Fig. 4. Vortices structure around new winglet (left), streamwise component of skin friction (right) 


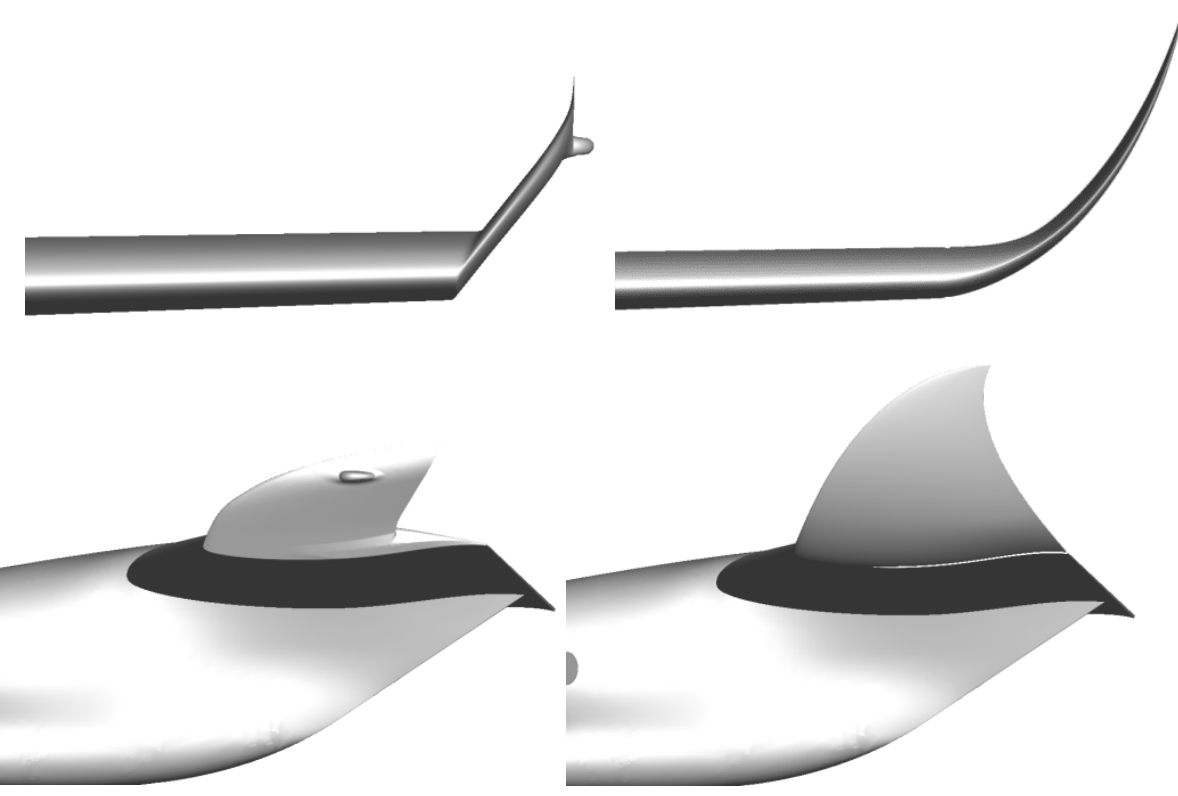

Fig.5. Comparison of the original (left) and optimized (right) winglet

The lift and polar curves of the simplified model with optimized winglet is depicted in Fig. 6. The green triangle depicts the aerodynamic characteristic of the baseline configuration with original winglet corresponding to the cruise condition. It should be emphasise that the baseline configuration does not have a slot between winglet and horn aerodynamic balance of the aileron. The winglet is "active" in the range of higher AoA. The effect of the slot between the wing and winglet can be seen on the vortices in Fig. 4.
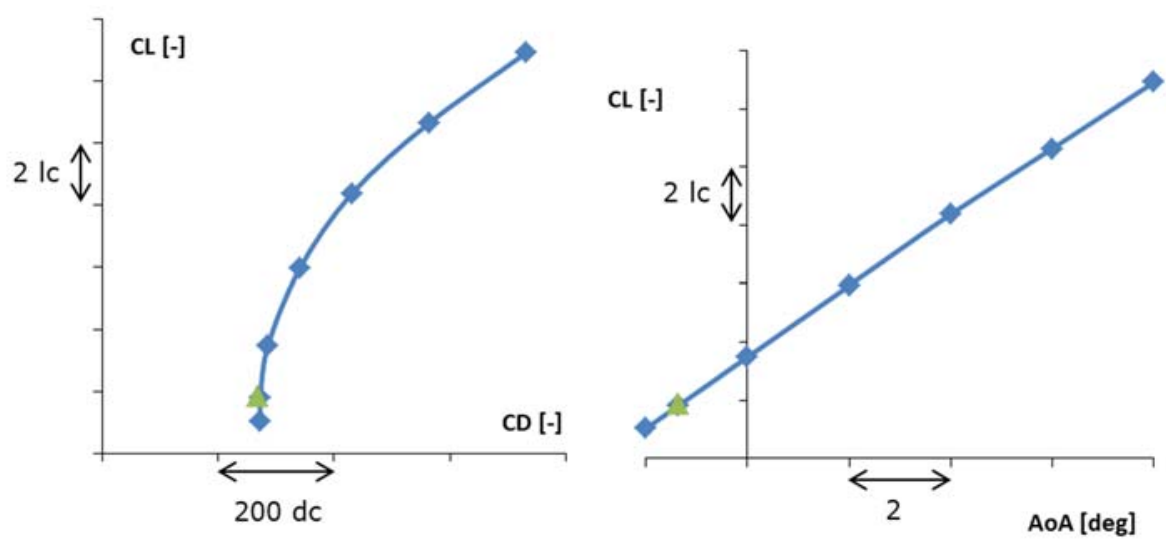

Fig.6. Polar curve of the optimized winglet

\subsection{Aerodynamic loading}

The critical cases from the loading of the wing and winglet were calculated in order to obtain the values of the forces and moments for further evaluation of the winglet's and wing's

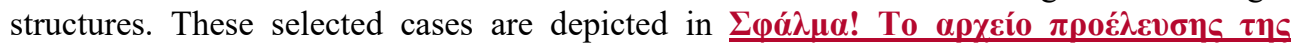

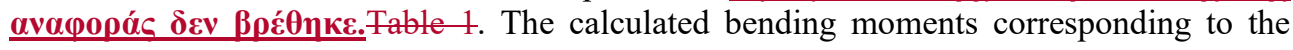


selected cases are depicted in Fig. 7. These moments were evaluated especially at the specific cross sections along the wing's span (see Fig. 8) defined in [6]. Due to the side slip angle for the cases marked B03 and B05, the bending moments of both wings were calculated.

Table 1. Definition of the critical cases

\begin{tabular}{c|c|c|c|c}
\hline Critical for & Case & Velocity [m/s] & $\alpha$ [deg] & $\beta$ [deg] \\
\hline \multirow{3}{*}{ Winglet } & A04 & 72.08 & 17.24 & 0 \\
& B03 & 51.94 & 6.46 & -30 \\
\cline { 2 - 5 } & B05 & 72.08 & 1.4 & -20 \\
Wing & 237 & 105.56 & 5.2 & 0
\end{tabular}

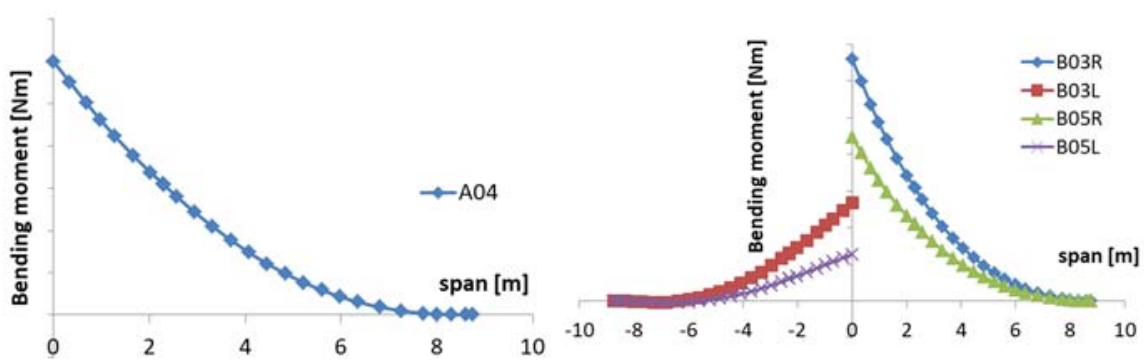

Fig.7. Bending moments for specified cases

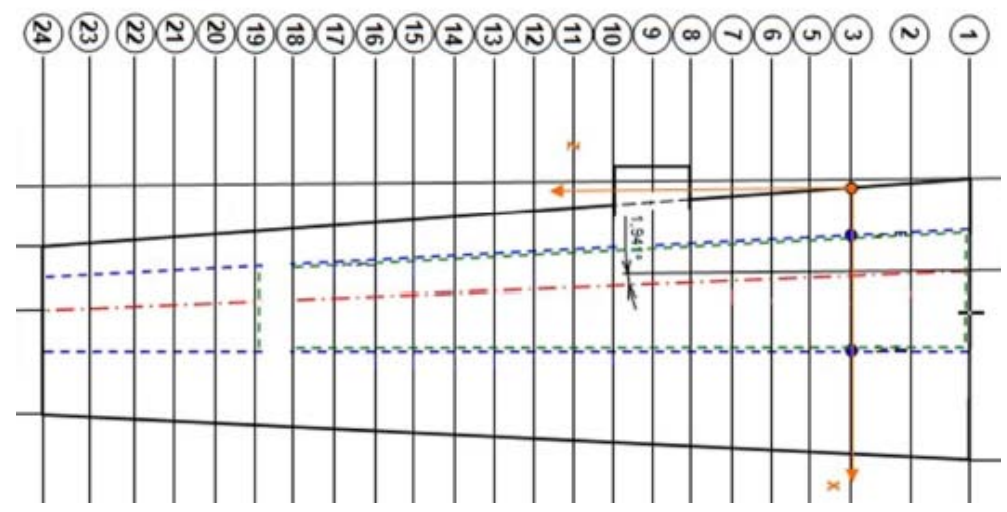

Fig.8. Defined cross sections for evaluation of the bending moment

The effect of the negative and positive gust on the wing's loading was also evaluated. Both, the dynamic and static effect on the wing's aerodynamic loading of the gust were calculated. The regimes corresponding to the gusts are depicted in Table 2. Due the higher loading, the static effect of the gust on the bending moment was considered and calculated, only.

Table 2. Regimes of the positive and negative gust 


\begin{tabular}{|c|c|c|c|}
\cline { 3 - 4 } \multicolumn{1}{c|}{} & Before gust & Gust effect \\
\cline { 2 - 4 } \multicolumn{1}{c|}{} & Velocity [m/s] & AoA [deg] & AoA [deg] \\
\hline Positive gust & 105.56 & -1.37 & 5.2 \\
\hline Negative gust & 105.56 & -2.31 & -8.27 \\
\hline
\end{tabular}

\section{Structural design}

The winglet design is based on the optimized aerodynamic shape and adapted to the outer wing rib section. The aerodynamic loads corresponding to the case A04 from the Table 1 were recalculated from the nodes of the CFD grid to the nodes of the FEM grid from the structure's dimensioning point of view. The ultimate load the factor 2.25 is applied. This factor is based on the safety factor on limit load of 1.5.

The structure is made from carbon fibre fabrics with local unidirectional reinforcement. The conception is a sandwich design to embed the antenna in the centre between lower and upper skin panel of the winglet. The boundary conditions of the FEM model of the winglet are depicted in Fig. 9.

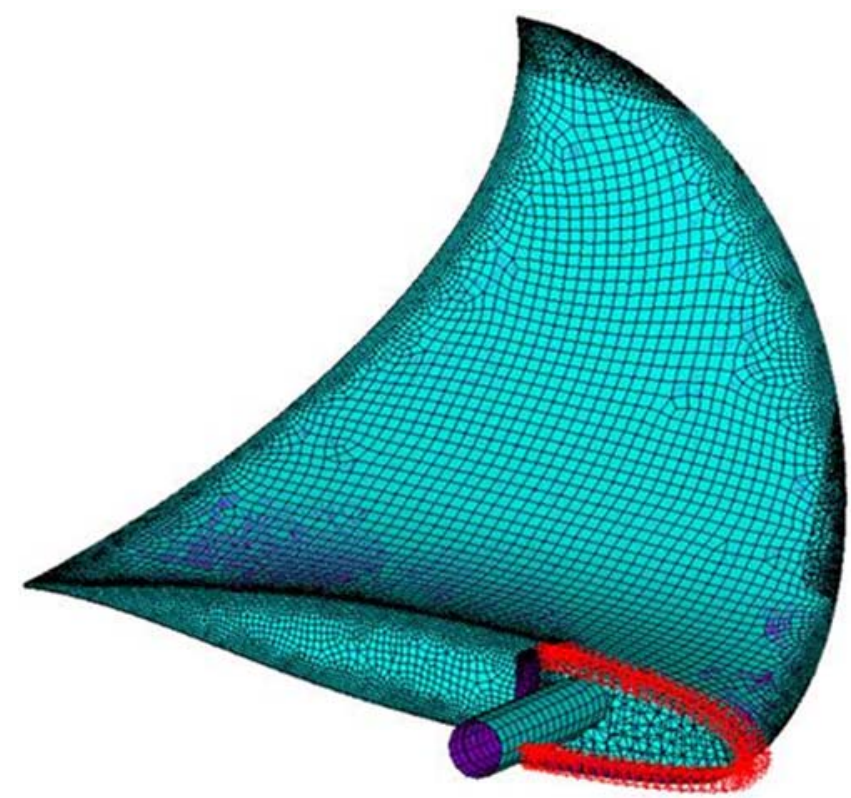

Fig. 9. Boundary conditions of the FEM model

Reaction forces at the tube introducing the bending loads into the wing as well as reaction forces at the bore holes at the outer rib together with the weight of the winglet was provided to Evektor for further verification of the wing's structure.

\section{Conclusions}

The winglet optimization for the AoA $=4 \mathrm{deg}$ by means of CFD method has been done. The optimized winglet reduced the overall drag by about 2 dc compared with the baseline geometry with original winglet. The surface of the new winglet is by about 2.38 times higher in comparison with the original winglet, which is favourable for integration of the high 
performance communication antenna. The larger surface and also the slot between the winglet and wing are the main reason for relatively small drag reduction.

Structural design of the winglet has been done according to the aerodynamic ultimate loads. The loads on the wing's end together with the winglet's weight were provided to the EVEKTOR to verify if the original wing's structure is suitable to sustain increased loads.

The design, modelling and analysis of the VHF antenna itself will follow.

\section{Acknowledgement}

All work described in this paper has received funding from the European Union's Horizon 2020 research and innovation programme under grant agreement No 723167, ACASIAS project.

This work was supported by The Ministry of Education, Youth and Sports of the Czech Republic from the Large Infrastructures for Research, Experimental Development and Innovations project IT4Innovations National Supercomputing Center LM2015070.

\section{References}

1. H. Schippers, J. Verpoorte, A. Hulzinga, C. Roeloffzen, and R. Baggen, "Towards structural integration of airborne Ku-band SatCom antenna," 7th European Conference on Antennas and Propagation (EuCAP), (2013), pp. 2963-2967.

2. ACASIAS project website: http://www.acasias-project.eu/

3. D.C. Montgomery, Design and Analysis of Experiments, $\left(7^{\text {th }}\right.$ ed., Wiley, Hoboken, 2009)

4. R.H. Myers and D.C. Montgomery, Response Surface Methodology, ( ${ }^{\text {rd }}$ ed., Wiley, Hoboken, 2009)

5. P. Vrchota and P. Hospodar, "Response Surface Method Application to High-Lift Configuration with Active Flow Control", J. of Aircraft, 49, pp 1796-1802, (2012)

6. X. Martinez, S. Algermissen, Z. Reznicek, P. Tobola, B. Veldman, A.-J. de Graaf, Ch. Heuts, R. Baggen, S. Steeger, J. Verpoorte and M. Müller, "Requirements and Specification Document”, Deliverable D1.1, ACASIAS project (2017) 